teams is crucial to success. In most countries, this requires an expansion of training places and an increase in the capacity of universities.

A second, connected conclusion is that the establishment of modern mental health services is not simply the rational dissemination of evidencebased models of care. Whereas the implementation of a national hospital plan can indeed be achieved by replicating the same building and workforce plans around the country, community services require major local adaptations and strong local commitments. Local leaders need to inspire change and instigate partnerships. Mostly, it is assumed that local psychiatrists can deliver this, and occasionally they can.

It needs to be recognised that the transformation of mental health services demands leadership and competence in change management. This should be considered a professional skill, as taught at management schools. However, it is all but absent from psychiatric curricula, and training opportunities are rare. It now needs to be accepted that such change management skills belong under the core competencies of psychiatrists.

Mental health reforms are proceeding around the globe, and the World Health Organization's
Global Action Plan and the European Action Plan identify some of the steps required. But essential are local commitment and the availability and skills of local change management, sustained over time. Respectful partnership between international guidance, national plans and local expertise is the recipe for progress.

\section{References}

Eaton, J., McCay, L., Semrau, M., et al (2011) Scale up of services for mental health in low-income and middle-income countries. Global mental health 4. Lancet, 378, 1592-1603.

Kohn, R., Saxena, S., Levav, I., et al (2004) The treatment gap in mental health care. Bulletin of the World Health Organization, 82 , 858-866.

Prince, M., Patel, V., Saxena, S., et al (2007) No health without mental health. Global mental health 1. Lancet 370, 859-877.

Wittchen, H. U., Jacobi, F., Rehm, J., et al (2011) The size and burden of mental disorders and other disorders of the brain in Europe 2010. European Neuropsychopharmacology, 21, 655-679.

World Health Organization (2001) The World Health Report 2001 Mental Health: New Understanding, New Hope. WHO.

World Health Organization (2012) Mental Health Atlas 2011 WHO.

World Health Organization Regional Office for Europe (2008) Policies and Practices for Mental Health in Europe. WHO Regional Office for Europe.
THEMATIC PAPER

\title{
Strategic vision for mental health and substance misuse in the Eastern Mediterranean Region
}

\author{
Khalid Saeed ${ }^{1}$ and Richard Gater ${ }^{2}$
}

${ }^{1}$ Regional Advisor, Mental Health and Substance Abuse, Division of Health Promotion and Protection, World Health Organization Regional Office for the Eastern Regional Office for the Easter
Mediterranean, Cairo, Egypt, Mediterranean, Cairo, Egypt,
email Saeedk@emro.who.int

${ }^{2}$ Senior Lecturer in Psychiatry, University of Manchester and Honorary Consultant Psychiatrist, Lancashire Care NHS Foundation Trust, UK
The Eastern Mediterranean Region of the World Health Organization has recently developed a comprehensive strategy and action plan to promote mental health and provide for the integrated prevention, treatment and rehabilitation of mental, neurological and substance use disorders. By strengthening national mental health policies, plans and legislation, scaling up integrated services, capacity-building, promoting human rights and prioritising vulnerable groups, the strategy aims to improve mental health and to help countries achieve their national development objectives.

The Eastern Mediterranean is one of the six regions of the World Health Organization (WHO). Its 23 member countries, from Pakistan in the east to Morocco in the west, have a combined population of almost 600 million (10\% of the global population). The region is undergoing rapid demographic, sociocultural and political transition and several countries are experiencing humanitarian emergencies. This has resulted in migration, internal displacement, unplanned urbanisation and changes in family role, which pose a threat to health and impair the capacity of health systems to deliver services. Wealth from the discovery of oil has facilitated significant improvements in education, literacy and life expectancy in some countries, while others are among the poorest in the world.

Mental, neurological and substance (MNS) disorders account for the loss of $11 \%$ of disabilityadjusted life-years and for $27 \%$ of the years lived with disability in the region (WHO, 2004). Despite the burden and economic impact of MNS disorders, the median annual investment in mental healthcare of US $\$ 0.15$ per person in the region's countries (WHO Regional Office for the Eastern Mediterranean, 2010) is well below the US\$3-9 needed for a recommended package of costeffective mental health interventions in low- and middle-income countries (Hyman et al, 2006).

The past decade has witnessed a number of global initiatives to improve mental health, 
culminating in the World Health Assembly resolution 'The global burden of mental disorders and the need for a comprehensive, coordinated response from health and social sectors at the country level' (WHO, 2012). The WHO's MIND (Mental Health In Development) programme encourages countries to recognise that mental health is central to economic progress, and supports the development of mental health policy, planning, legislation and integrated services in a manner that promotes human rights and quality of care.

\section{Regional strategy on mental health and substance misuse}

In 2011 the WHO Regional Committee for the Eastern Mediterranean endorsed a regional strategy on mental health and substance misuse (WHO Regional Office for the Eastern Mediterranean, 2012a), providing the foundation for the development of national strategies and action plans for the next 5 years. The strategy has six components, each with defined objectives and suggested activities at regional and country level, tailored to the resources of the countries, accompanied by a framework for monitoring and evaluation of their implementation.

\section{Strategic component 1 . Strengthen leadership and political commitment to mental health}

The development and maintenance of an integrated mental health system require a well informed, government-led commitment, articulated through effective health and social sector policies, strategies, plans and legislation. Of the countries in the Eastern Mediterranean Region, $75 \%$ have officially approved mental health policies, 90\% have mental health plans and $55 \%$ have dedicated mental health legislation (WHO Regional Office for the Eastern Mediterranean, 2012b).

The objectives of this component are to help set up national mental health units within ministries of health to develop, resource, implement and monitor mental health and substance misuse policies, plans and legislation, and to ensure intersectoral collaboration for mental health promotion. Regional activities include the creation of a mental health advisory group to review, guide and advise on implementation of the strategy. Country-level activities include review of existing mental health and social policies, strategies, plans and legislation to see whether they meet contemporary standards and are adequately resourced.

\section{Strategic component 2. Scale up integration of mental health in primary healthcare}

Although primary healthcare (PHC) has been affirmed as the cornerstone of efficient healthcare since 1978, progress in making mental healthcare available through PHC has been patchy (WHO \& Wonca, 2008; Eaton et al, 2011). A crude measure demonstrates that overall progress towards the integration of mental health into PHC can be achieved irrespective of country income (Table 1).
Table 1

Progress towards the integration of mental health into primary care: sum of seven relevant WHO Atlas indicators by World Bank income group (each dot represents a country in the WHO's Eastern Mediterranean Region)

\begin{tabular}{|l|l|l|l|l|}
\hline $\begin{array}{l}\text { WHO Atlas } \\
\text { indicator }\end{array}$ & \multicolumn{4}{|l|}{ World Bank income group } \\
\hline & Low & $\begin{array}{l}\text { Lower } \\
\text { middle }\end{array}$ & $\begin{array}{l}\text { Upper } \\
\text { middle }\end{array}$ & High \\
\hline 1 & & $\cdots$ & $\bullet$ & \\
\hline 2 & & $\cdots \bullet$ & & $\bullet$ \\
\hline 3 & & $\bullet$ & & $\bullet$ \\
\hline 4 & $\bullet$ & $\bullet$ & & $\cdots$ \\
\hline 5 & $\bullet$ & $\bullet$ & & \\
\hline 6 & & & & \\
\hline 7 & & & $\bullet$ & \\
\hline
\end{tabular}

This component aims to increase coverage of community-oriented mental healthcare by enhancing the capacity of PHC workers through training, support and supervision, task-shifting and robust referral/back-referral mechanisms. An example of a regional-level activity is the establishment of a regional working group of experts to collaborate in the delivery of training packages based on the WHO's mental health Gap Action Programme Intervention Guide (mhGAP-IG) (WHO, 2010). Country-level activities include the review and reformulation of medical and nursing curricula to meet the needs of integrated community-oriented services.

\section{Strategic component 3. Strengthen secondary and tertiary mental health services}

Almost half of the region's mental health workforce is in mental hospitals (WHO Regional Office for the Eastern Mediterranean, 2010). The region has half the global rate of out-patient facilities, and only $1 \%$ of out-patient facilities offer followup community care. Other community facilities, such as day treatment, psychiatric beds in general hospitals and community residential facilities, are sparse in most of the region's countries.

The objectives of this component are to establish in-patient units in general hospitals, community out-patient clinics and day care facilities, to support PHC and to strengthen the capacity of the specialist mental health workforce, consistent with their role in the mental health system. Examples of regional activities are a review of postgraduate training programmes for mental health professionals and the development of a framework of training standards. Country-level activities include the decentralisation and reorientation of mental health services.

\section{Strategic component 4. Identify and prioritise vulnerable persons}

This component addresses the ethical imperative to provide for more vulnerable sections of society, such as women, children and adolescents. The objectives are to identify vulnerable persons and collaborate with other sectors to ensure that 
appropriate mental health services are made available for them. Examples of regional-level activities are the development of regional preparedness and response plans for mental health and psychosocial support in emergency settings. Country-level activities include the implementation of the regional strategic directions and actions for maternal, child and adolescent mental healthcare.

\section{Strategic component 5. Intersectoral coordination and collaboration to promote mental health and prevent mental disorders}

Mental health services have tended to be insular, despite opportunities to link with existing prevention and health promotion programmes to realise mutually beneficial outcomes. School-based activities promoting mental health and preventing mental disorders are present in $85 \%$ of Eastern Mediterranean countries, but in most these cover less than $20 \%$ of schools (WHO Regional Office for the Eastern Mediterranean, 2010). There are fewer links with housing and employment, which limits opportunities for rehabilitation. Service user and family associations are present in 30\% and $35 \%$ of the region's countries, and few of these are involved in the formulation and implementation of plans (WHO Regional Office for the Eastern Mediterranean, 2012b).

The objectives of this component are to increase awareness and reduce the stigma of MNS disorders and their treatment, through partnerships and collaboration. An example of a regional activity is collaboration with other United Nations agencies and non-governmental organisations (NGOs) to incorporate mental health into health and social sector programmes. Country-level activities include high-level collaboration with other government departments and bottom-up engagement in partnership with NGOs and others, ensuring wide access to information and public awareness programmes.

\section{Strategic component 6. Promote operational research}

Research informs best practice and gives the evidence base for policy decisions and actions, but only $1.8 \%$ of research publications on mental and substance use disorders are from North Africa or the Middle East (Patel et al, 2007). Accurate and up-to-date information systems can monitor the implementation of services and help identify areas for service improvement. Eighty per cent of Eastern Mediterranean countries collect and publish national data on mental hospital admissions and psychiatric out-patient contacts, but information about mental health provision in community settings and PHC is published in fewer countries (20-65\%) (WHO Regional Office for the Eastern Mediterranean, 2012b).

The objectives of this component are to establish comparable information systems and to strengthen mental health operational research appropriate to each country's needs and resources. Examples of regional activities are support for the development of an integrated system of databases across the region, and the facilitation of collaborative links between researchers within and outside the region. Country-level activities include the integration of mental health indicators within national health information systems and the establishment of national forums to identify and lobby for research priorities.

\section{Conclusions}

The principles of and evidence for decentralised community-oriented mental health services integrated with primary and general healthcare are not new. Despite many attempts, integration remains patchy, funding is inadequate and resources continue to be centralised in mental hospitals.

The present strategy aims to reinvigorate efforts to improve mental health provision (components 2 and 3) but recognises that this can be achieved only by strengthening leadership (component 1), working in partnership (component 5) and promoting operational research to provide evidence for placing mental health higher on the social and development agendas (component 6). The emphasis on the development of national policies, plans and legislation, scaling up integrated services, capacity-building, promoting human rights and prioritising vulnerable groups can create a positive region-wide response to the WHO's MIND call for synergy between mental health improvement and national development.

\section{References}

Eaton, J., McCay, L., Semrau M., et al (2011) Scale up of services for mental health in low-income and middle-income countries. Global Mental Health 4. Lancet, 378, 1592-1603.

Hyman, S., Chisholm, D., Kessler, R., et al (2006) Mental disorders. In Disease Control Priorities in Developing Countries (2nd edn) (eds D. T. Jamison, J. G. Breman, A. R. Measham, et al), pp. 605-626. World Bank.

Patel, V., Araya, R., Chatterjee, S., et al (2007) Treatment and prevention of mental disorders in low-income and middle-income countries. Lancet, 370, 991-1005.

WHO (2004) Disease and Injury Estimates for 2004. WHO Available at http://www.who.int/healthinfo/global_burden_disease/ estimates_regional/en/index.html (accessed 15 August 2012).

WHO (2010) mhGAP Intervention Guide for Mental, Neurological and Substance Use Disorders in Non-Specialized Health Settings. Mental Health Gap Action Programme, WHO.

WHO (2012) Sixty-Fifth World Health Assembly Resolution - The global burden of mental disorders and the need for a comprehensive. coordinated response from health and social sectors at the country level. WHA65.4. WHO

WHO \& Wonca (2008) Integrating Mental Health into Primary Care: A Global Perspective. WHO \& World Organization of Family Doctors (Wonca).

WHO Regional Office for the Eastern Mediterranean (2010) Mental Health Systems in the Eastern Mediterranean Region: Report Based on the WHO Assessment Instrument for Mental Health Systems. EMRO Technical Publications Series No. 37. WHO

WHO Regional Office for the Eastern Mediterranean (2012a) Regional Strategy on Mental Health and Substance Abuse. WHO $\mathrm{EM} / \mathrm{MNH} / 191 / \mathrm{E}$. WHO.

WHO Regional Office for the Eastern Mediterranean (2012b) Mental Health Atlas 2011. Resources for Mental Health in the Eastern Mediterranean Region. WHO (in press). 